\title{
The Influence of Public Values on User Participation in e- Government: An Exploratory Study
}

\author{
Anonymous Author(s)
}

\begin{abstract}
In the last three decades, governments and public administrations have strongly increased their use of information and communication technologies (ICT) to improve the service delivery towards their users, i.e. citizens, businesses or other public bodies. This development of ICT solutions must be performed in close collaboration with the end-users so that the e-government services are aligned with their requirement and needs. Gathering the input from the users can be performed through the use of participation methods such as interviews, workshops or dedicated softwares.

However, the choice of the method is very context-specific and public servants tend to lack proper guidance about the appropriate method to use. Public values at the core the strategy of the organization and constitute an essential context factor to consider. Therefore, in this paper, we analyze how public values impact practitioners in their selection of method for the development of e-government services. Through the analysis of four e-government projects, we were able to understand the drivers behind user participation decisions. Furthermore, we formulate recommendations for practitioners to give them guidance about their choice.
\end{abstract}

\section{Keywords}

User Participation; Public Values; e-Government; Context Factor

\section{INTRODUCTION}

Governments and their public administrations increasingly use information and communication technologies (ICT) in an attempt to improve the service delivery towards their users, whether these are citizens, businesses or even other public bodies. This ICT use is qualified as "e-government" in the existing literature [1]. In order to answer the concrete problems of their users and to be aligned with their requirements, the participation of users in the development of e-government services is often qualified as a good practice in this context [2]. This participation can happen at different development stages, such as during requirements engineering or testing, and can be implemented by means of different participation methods, such as interviews, workshops or surveys. However, civil servant are sometimes reluctant to include the users in the development process. There can be several reasons such as a lack of knowledge on potential methods, a lack of time or other resources, user input considered too complex to integrate and so forth. Another key challenge, related to the lack of knowledge on potential methods, is the wide variety in existing participation methods [29]. Indeed, some methods are more relevant than others, depending on the specific context (users' characteristics, their motivation, the organizational culture, the project stage, etc.). What is however often forgotten in both public administration and information systems literature, is the relation between the public values strived for by the civil servants working on e-government projects and the inclusion of users in those projects. Public values are an important context factor that can be described as 'normative concepts that are used to give direction to public action and/or legitimize such action', they steer the direction and choices made by civil servants $[18,20]$ and are as such also expected to impact the choice on the type of user participation method.

The objective of this paper is to examine the impact of public values on the choice of user participation methods, thereby to understand how public values impact policy makers in their selection of user participation methods for the development of e-government services. Since the link between public values and user participation methods has not been documented yet in literature, we performed an exploratory study with the aid of qualitative and quantitative techniques. We selected four illustrative projects where user participation was applied in an e-government context. To help us understand this link qualitatively, we designed a semi-structured interview guide and conducted one interview per project to get a better understanding of the public values strived for by the respondents as well as the participation methods used in the respective projects. To help us understand this link quantitatively, we performed a ranking of the public values for each project. This combination of methods helps us to gain a deeper 
understanding of the complex phenomenon that is the influence of public values on user participation in an egovernment context. This paper contributes at several levels. The examination of several cases where user participation methods were applied and brought benefits for the stakeholders depending on their drivers, results in a set of management recommendations to help the decision-makers choosing which method to implement in their organization.

Section 2 details the literature of user participation and its link with public values in the context of e-government, . Section 3 explains the exploratory research method we applied. Section 4 presents the influence of the values on user participation which is then discussed in Section 5. Section 6 presents the limitations and further research leads to answer. Finally, Section 7 summarizes the contributions and provides closing comments.

\section{Background}

\subsection{User Participation}

User Participation has always been considered as a key success factor in information systems development as it allows the functionalities of the system to answer to the users' requirements[16]. There exist different participation methods to collect the input of users in the development of information systems. For the specific case of e-government, [27] there are eight different methods reported that are briefly described hereunder:

- Interviews: This direct interaction method is used by software developers to gather input from users (often in the requirements engineering phase).

- Representation in the project team: Salient intermediaries users can be considered as partners and intermediaries in different stages of the project to give guidance to key public servants.

- User workshops: This method allows the interaction with a selected group of representative users

- Answer to surveys: Online, phone or in-person surveys can be used to collect insights from a large number of users.

- Dedicated Software: This method, to be used via online platforms or applications, can be used to collect citizens' ideas and needs. This method is currently often used in a smart city context [5].

- Social Media: Social Media is considered as a lead to improve software development practices [33].

- Innovation Ecosystem: Insights from potential users can also be collected thanks to new user-driven open innovation ecosystems such as Living Labs [13] or Hackathons [11].

- Usability tests on prototypes: This methods allows to present a non-finished software to its potential users to collect feedback and improve it.

However, despite this wide range of methods, user participation is not always implemented in practice due to some constraints (lack of time, lack of methodological expertise, or a too complex input to integrate) [27]. On the other hand, these methods are sometimes used as a "silver bullet" hoping that they will solve every development problem [17]. A further analysis of the contextual factors to reach a better situated user participation is thus needed. In this paper, we argue that the public values constitute one of the main context factors to consider.

\subsection{Public Values}

Different context factors impact the choice to make use of a Participation Method and the specific choice of a certain type of Participation Method. Indeed, context factors will impact the behavior and choices made by the civil servants deciding on User Participation Methods. These context factors result from the users' characteristics and motivation [35], the culture of a country [3], the specificities of the organization or functioning of the public administration [28] or the stage of the e-government project [30]. All those external factors will have an impact on the choices made in the development of information systems, so those factors can be considered to be contextual factors impacting the internal choices. This paper takes a specific look at the effect of public values, which forms an important factor within the group of contextual factors. Indeed, the focus of this paper lies on the public values of civil servants which influence the choice of the type of participation methods.

In 1952, [22] provided one of the first descriptions of a 'value'. The author argued that it is 'a conception, explicit or implicit, distinctive of an individual or characteristic of a group, of the desire which influences the selection from available modes, means and ends of actions' [22]. Whereas this definition correctly points to the higher level rather than individual ideas and thought, the authors' focus lies however only on values in general and not on public values. [10] states that public values provide direction to three relation. It includes "[1] the rights, benefits and prerogatives to which citizens should (and should not) be entitled, [2] the obligations of citizens to society, the state and one another; and [3] the principles on which governments and policies should be based"[10]. This is a highly relevant description 
as it points to the relation between the public administration and its civil servant in relation to external users, here described as 'citizens'. This description as such makes the connection to new approaches on user participation methods. Indeed, public values do not only have an internal public administration meaning, but are highly important in steering and regulating the relation with society.

We define public values, in line with [7] as 'the ideals, coined as principles, to be followed when producing a public service or regulating citizens' behavior, thus providing direction to the behavior of public servants.'. Our specific interest lies in the public values of the public servants involved in the development of information systems. Those public values steer the behavior of public servants: They influence the behavior and decisions of public servants, and are as such also expected to influence their decisions on participation methods. Until now, however, and to the authors knowledge, no research has been conducted on what public values, and balances between those public values, influence decisions on participation methods. This paper aims to make a contribution to this fundamental missing link on the relation between the heart of public service and its relation to its users, as 'the notion of public values is at the heart of good governance' [7, 21].

On the basis of recent public values research [18], a number of public values have been selected, emphasizing three clusters of public values which are expected to influence the decision making on making use of user participation methods. The first cluster focuses on service delivery. The public servant might decide to include users in order to increase the quality of the service that is provided towards the users. Secondly, there is a cluster on a 'better relationship' between public servants and the users. Focus lies hereby on the respect between both parties in the development of services. The third cluster focuses on the democratic quality and, especially, the perceived willingness of public servants to ensure 'better democratic quality'. An overview of the different public values that are related to each of those three clusters can be found in Table 1. It was decided to make use of this typologies for three reasons. First of all it is concise typology which makes it suitable for an exploratory study. Secondly, the typology has been built from theory but has already been used in practice. Finally, and most importantly, the typology was used for research on participation by citizens in the development of services. This topic is closely related to our research, which makes it highly suitable for application in this research [18].

Table 1. Public Values (Source: [18] )

\begin{tabular}{|l|l|l|}
\hline Better services & Better relationship & $\begin{array}{l}\text { Better democratic } \\
\text { quality }\end{array}$ \\
\hline Efficiency & Mutual Learning & Participation \\
\hline Effectiveness & Trust & Empowerment \\
\hline Quality & $\begin{array}{l}\text { Being considerate of } \\
\text { clients } \\
\text { accountable, needs: } \\
\text { responsive, and } \\
\text { transparent }\end{array}$ & Inclusion \\
\hline Satisfaction & $\begin{array}{l}\text { Being considerate of } \\
\text { clients' capacities }\end{array}$ & Social capital \\
\hline Sustainability & Reciprocity & \\
\hline & Individual freedom & \\
\hline
\end{tabular}

\subsection{Theoretical Model}

As indicated above, the aim of this exploratory research is to gain a deeper understanding of the relationship between the public values that are strived for in an e-government project and the types of user participation methods which are chosen. This logic is represented in Figure 1. Our research focus in this paper lies in the hypothesis that the choice of "User participation Method" is influenced by the "Public Values" that is strived for in an e-government project. As explained above, we relied on the review of [29] for the methods and on [18] for the values. It is important to underline that within one project several user participation methods can be used. According to us, those different user participation methods can be influenced by the different public value clusters. In order to first explore this theoretical link, we chose to study the influence of values on participation methods by analyzing quantitatively and qualitatively four projects. This will be explained in the next section. Thanks to this exploratory study we formulate hypotheses to guide practitioners and that will constitute a basis for researchers to further investigate this link. 
Figure 1: Theoretical Model

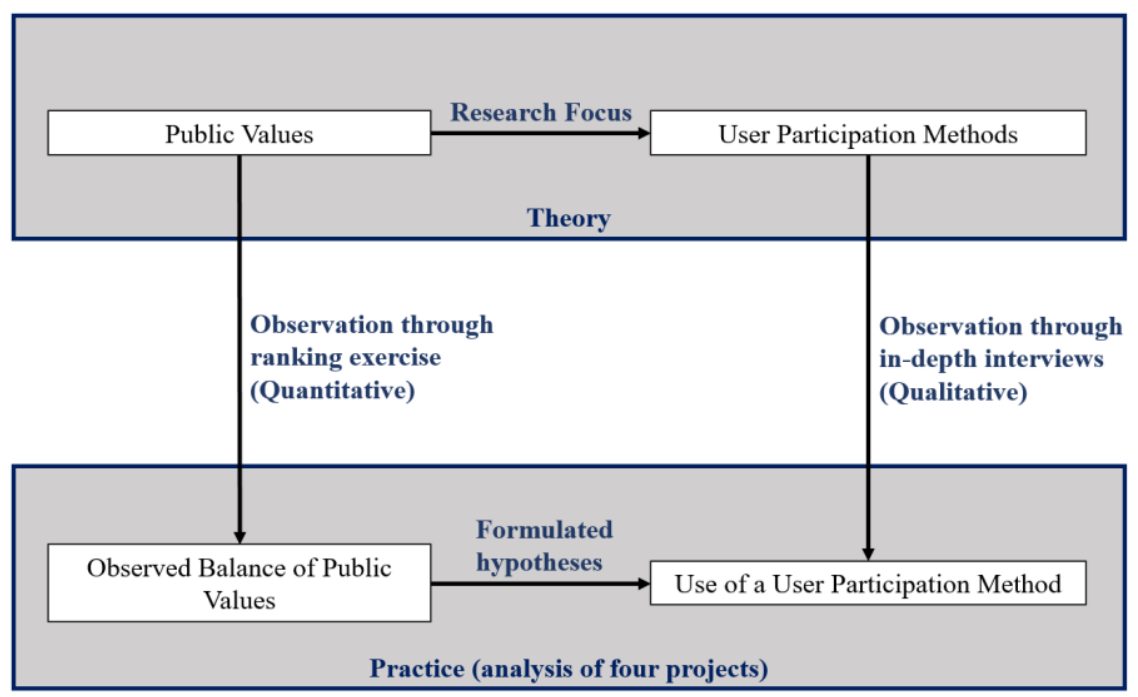

\section{Methodology}

In order to collect insights about the influence of public values on user participation methods, we performed an exploratory study of four projects to validate the theoretical model previously described [32]. We chose these four projects based on several criteria: It is part of an ongoing egovernment strategy, we had knowledge about the implementation of participation methods in the project and finally, we knew different members of all four projects.

Each project was analyzed qualitatively thanks to (1) an indepth interview with a key stakeholder and (2) a quantitative ranking exercise. The exploratory nature of this study is a consequence of the lack of empirical research on the influence of public values on e-government service development.

To understand the importance of public values within each project, we performed a quantitative ranking exercise where we presented the interviewees with the different values from Table 1 and asked them to rank them in function of their importance they had in the project. To further complete this information, we decided to apply a qualitative approach, with a focus on in-depth interviews. This qualitative information helped to better understand the importance of the public values, the user participation methods used and the relation between the two. In order to perform the interviews, we design an interview guide (that can be found in the Appendices Section) following the best practices from research [9]. We made intensive use of probing questions in order to gain knowledge about the public values. The interviews were analyzed following simple coding by the authors of this paper [24]. In order to realize this coding, we mapped the words formulated by the interviewees to the chosen taxonomy of values [18].

As stated by [19], this multi-method approach combines a qualitative and quantitative analysis to have a more informed, complete, balanced, and useful research results. The ranking exercise allowed us to have quantitative data about the public values whereas the interviews allowed us to have information about their impact on development practices and user participation methods $[4,9]$.

The four projects are presented in Table 2.

Table 2. Analyzed Projects

\begin{tabular}{|l|l|l|l|}
\hline \multicolumn{1}{|c|}{$\begin{array}{c}\text { Governmental } \\
\text { Body }\end{array}$} & $\begin{array}{c}\text { Governmental } \\
\text { Level }\end{array}$ & $\begin{array}{c}\text { Date of the } \\
\text { interview }\end{array}$ & $\begin{array}{l}\text { Function of the } \\
\text { interviewee }\end{array}$ \\
\hline $\begin{array}{l}\text { National } \\
\text { Geographic } \\
\text { Institute } \\
\text { (Belgium) }\end{array}$ & $\begin{array}{l}\text { Belgian federal } \\
\text { level }\end{array}$ & $14 / 12 / 2018$ & Project Manager \\
\hline $\begin{array}{l}\text { City of Namur } \\
\text { (Belgium) }\end{array}$ & $\begin{array}{l}\text { Belgian local } \\
\text { level }\end{array}$ & $09 / 01 / 2018$ & $\begin{array}{l}\text { Head of Data } \\
\text { Office }\end{array}$ \\
\hline $\begin{array}{l}\text { City of La } \\
\text { Louvière } \\
\text { (Belgium) }\end{array}$ & $\begin{array}{l}\text { Belgian local } \\
\text { level }\end{array}$ & $19 / 12 / 2018$ & $\begin{array}{l}\text { E-Government } \\
\text { Project Manager }\end{array}$ \\
\hline $\begin{array}{l}\text { City } \\
\text { Linkoping } \\
\text { (Sweden) }\end{array}$ & $\begin{array}{l}\text { Swedish Local } \\
\text { level }\end{array}$ & $07 / 12 / 2018$ & $\begin{array}{l}\text { Head Digitalization } \\
\text { Def }\end{array}$ \\
\hline
\end{tabular}

The first project focuses on the analysis of the development process of a tracking tool for high ranked officials during officials summits in the Brussels Capital Region (Belgium).As a result of the high amount of official summits of the North Atlantic Treaty Organization (NATO) and the 
European Union (EU) the Belgian Ministry of Interior Affairs (MIA) asked for the development of a precise tracking tool to be used by all Belgian partners involved in the organization of those summits. This tracking tool would allow all involved organizing partners to follow the live movements of high ranked officials, such as Heads of States and Prime Ministers. The Belgian Crisis Centre, part of the MIA, organized the development of the tool together with the Belgian National Geographic Institute, an external consultant specialized in agile methodologies and ASTRID, a semi-private organization responsible for emergency service communication coordination which is governed by the MIA. Also the Belgian federal police, the decentralized fire fighters, the Chancellery of the Prime Minister and the Ministry of Foreign Affairs were involved but only as users. Those last actors were not part of the development team. A short time period of less than six months was available for the development of the service.

The second project focuses on the digitalization of the city of Linkoping in Sweden. The main goal of this project (running since early 2018 is to accelerate the digitalization of the municipality and the companies it owns. Three persons are responsible for this: One head of digitalization at strategic level and two business developers at operational level. At the time of this study, the focus was set on building a framework to ensure the development of a coherent strategy in order to answer to the requirements and needs of its users.

The third project focuses on the digitalization of the city of La Louvière in Belgium, that is running since February 2017. This project aims at improving the internal functioning of the administration as well as the services offered to the users. Three persons are involved in this project: The head of digitalization, the e-government project manager and the process analyst. The focus lies on the development of an online portal for citizens to use.

The fourth project focuses on the digitalization of the city of Namur in Belgium, that has been running for more than three year. Here also, the project aims to improve the internal functioning through the development of interoperable applications. The main focus currently lies on the improvement of an Open Data portal and an end-to-end rethinking of the data flow in the administration. This is handled by the Head of the Namur Data Office in collaboration with the IT department.

\section{Results}

In this section we present the balance between the different public values, both at a clustered and non-clustered level among the four projects. Afterwards, we analyze the choice of the participation method(s) in the four projects and present the drivers between these choice as explained by the different respondents.

\subsection{The Balance of Public Values}

In order to answer the research question, which focuses on the causal relation between public values and user participation methods, it is first important to understand how the different respondents balance the different public values: what are, according to the respondents, the key public values that were strived for in the projects they worked on? The respondents were asked in to rank the 15 public values, from most important to least important. By ranking the public values, the respondents also assigned a number of points to each public value: The first public values received 15 points, the second 14 points and so on for the next 13 values. The last value received 1 point.

Before going into the public value cluster balance for each individual project, Figure 2 presents the aggregated percentages. We obtained this result by calculating the total sum of points for each of the value clusters for the four projects and by dividing this by the total sum of all values points for the four projects (e.g. 'Better services' (BS) received 181 points in total, this was divided by 420 as this is the total number of points to be divided when ranking the 15 public values. This gives $37 \%$ in total). What is immediately clear from this balance is that the highest percentage $(42 \%)$ is dedicated to the public values that fall in the cluster 'Better relationship' (BR). This is immediately followed by the BS cluster with $37 \%$. The cluster 'Better democratic quality' (BD) only received $20 \%$ of the total points. There is as such, for the four projects together, a clear preference for the BR and BS clusters.

Figure 2: Public Value Clusters

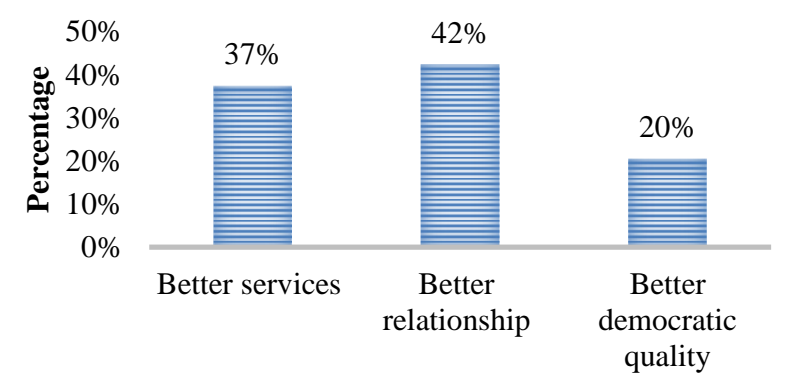

Aggregated Value Clusters for all projects 
Figure 3: Influence of Public Values on User Participation Methods

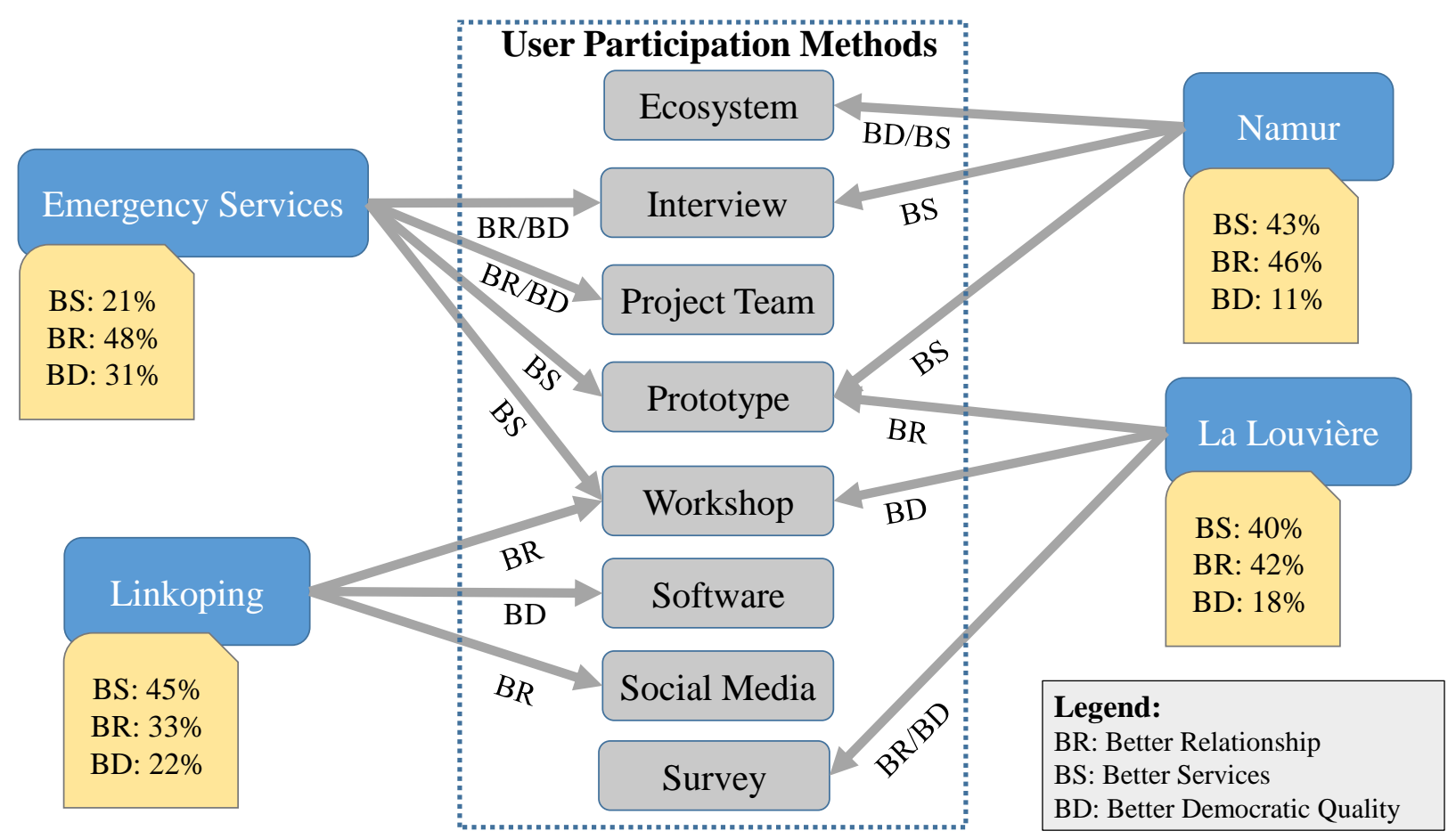

When looking in more detail at the balance of the public value clusters for the four individual projects, as presented in Figure 3, then it appears immediately that there is not a single public value cluster that receives more than $50 \%$ of the points. All clusters, in all four projects, remain under $50 \%$, with the maximum being reached for the Emergency Services project by BR with $48 \%$. Secondly, the Digitalization Linkoping project is the only one in which the BS cluster is the one with the highest percentage. The three other projects all three have BR as their main public value cluster. For the Digitalization Namur and the Digitalization La Louvière projects, this cluster is however immediately followed by the BS cluster. Those two projects have as such a more balanced public value approach than the other projects.

A third interesting finding is the fact that for Digitalization Linkoping, Digitalization La Louvière and Digitalization Namur the BD cluster only follows as third cluster with respectively $22 \%, 18 \%$ and $11 \%$ of the points being assigned to the public values of this cluster. Another interesting finding is the fact that the BR cluster scores the highest in the Digitalization Emergency Services project, followed by the BD cluster. The difference between those two clusters is also the highest (17\%) difference between the first and the second cluster for the four projects.

\subsection{Influence of Public Values on User Participation Methods}

In this section, we analyze the influence of the public values previously identified, on the choice of user participation methods. Figure 3 details the different methods that were used in the four projects as well as the drivers behind the choices (represented by the labels on the arrows). These drivers were extracted from the in-depth interviews thanks to the coding analysis where the analysis allowed us to map the drivers to a specific cluster of public values.

The "Innovation Ecosystem" method was only used by Namur as the city leveraged its open data portals so that students use it to develop applications. It was a mean to increase the participation of users in the public domain (BD) but also a way to collect feedback to improve it (BS).

The "Interview" method was used by two projects. For Namur, it was a means to better understand the requirements of the public servants (BS). For the emergency services project, in contrast, it was performed to increase the participation and empowerment of the different stakeholders (BD), to improve their relationship with them (BR), to create more trust (BR) and to ensure that the team would sufficiently take into account client needs and capacities (BR). 
The "Representation in project team" was only used in the Emergency Services Project. It was deemed highly important to be accountable, responsive and transparent towards the users of the tool, elements which are part of the public value 'being considerate of clients' needs' (BR). Besides being focused on the clients' needs, the team also wanted to be considerate of clients' capacities (BR). Finally, the project team representation allowed to ensure participation (BD) and inclusion (BD)

Three projects applied "Usability Tests on Prototypes" but for different reasons. Namur and the Emergency Services used it as a way to improve the service (BS) whereas La Louvière used it as a way to show citizens that the egovernment portal is a viable alternative to more traditional procedures (BR).

Three projects applied "User workshops" but for different drivers. The Emergency Services project applied it to let requirements emerge (BS), Linkoping aimed at mutual learning between operational and strategical public servants for the digitalization strategy (BR) and La Louvière wanted to include people for each department so that they feel a part of the e-government strategy (BD)

Only Linkoping used "Social Media" as a way to improve the information delivery to citizens (BR). Only Linkoping also used "Dedicated Software" to collect the ideas of citizens to improve the digital strategy (BD).

La Louvière used "Answer to surveys" to let citizens give feedback on the portal and give ideas to improve their digitalization strategy (BD)

We must also note discrepancies between the quantitative insights on public values and the drivers for the use of participation methods expressed in the interviews. For instance, the main public value category driving the project of Linkoping is to reach BS. However, in the interviews, they mostly used participation methods to improve the relationships with their users and the democratic participation of citizens.

\section{Discussion}

A first element for reflection and discussion is the discrepancy in results between (1) the qualitative interviews in which the respondents made a connection between the public values and the user participation methods and (2) the quantitative public values ranking. When looking at the results of the quantitative ranking exercise, we see that the Linkoping project respondents puts the BS cluster first. The Emergency Services, La Louvière and Namur project respondents put the BR cluster first. We underline however that in the case of Namur and La Louvière, this cluster is immediately followed by the BS cluster. With this knowledge, it is interesting to make the connection to the qualitative interview results presented in Figure 3. Indeed, the results show that the user participation methods used and the public values that were strived for are not always connected to the results of the quantitative ranking exercise. This is rather surprising, and underlines the need for more research on this topic. At the same time, we try to provide a first potential explanation for this: The quantitative ranking exercise probes the importance of public values throughout the whole project, whereas the qualitative interviews look to the connection between certain user participation methods and public values, which is a more specific aspect of the project. For the project of La Louvière for example, the first public value to achieve within the overall project was 'effectiveness' (part of BS). In the user participation methods that were applied, emphasis was however put on prototype testing, workshops and surveys which fall, according to our research results, in different value clusters, i.e. respectively $\mathrm{BR}, \mathrm{BD}$ and $\mathrm{BR} / \mathrm{BD}$. This could partially explain the difference. Another potential explanatory factor is the fact that working on the realization of a certain public values can lead towards the realization of other public values. For example, more trust can lead towards greater effectiveness and / or service quality [14].

The results also revealed that for some interviewees such as the city of Linkoping, the user participation methods are not considered as an effective way to achieve the main public values driving their projects. However, we argue that it can be an effective way to reach it and we here suggest a decision aid to do so in the following section. Therefore, based on the alignment between the balance of values (quantitative) and the methods used (qualitative), we formulate hypotheses about the use of specific methods depending on the values driving the organization. These hypotheses are derived from the results observed in the four studied projects and underlined thanks to examples found in the scientific literature. As a next step of the research, a diagnosis questionnaire to know whether or not to go towards participation and which method to use would be a useful decision support aid for practitioners. 
Figure 4: Decision aid based on hypotheses

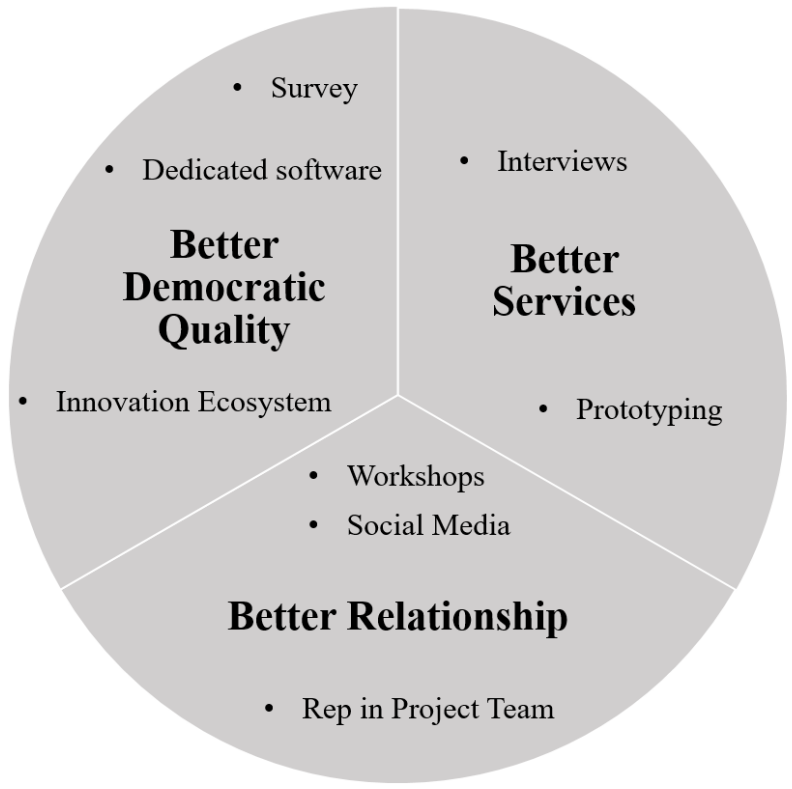

If the organization aims at reaching Better Services, we recommend the use of interviews or prototyping as they constitutes easy-to-use methods that do not consume a lot of time. Interviews allow a better understanding of the business domain and to understand the requirements more easily and can be used in the requirements engineering phase easily [6]. On the other hand, prototyping allows a fast presentation of the e-government service to collect feedback on it. For instance, [34] suggested a rapid prototyping process in the context of e-government services

If the organization aims at reaching Better Relationships, we recommend the use of representatives in the project team, social media or workshops. Workshops allow to make users discuss with each other and truly express their voice with the aid of innovative techniques such as visualization tools or improvisation principles [23, 25]. The representation in the team allows to give control over the process to lead users. and therefore enables the process to be transparent to them [12]. Finally, Social Media allows to deliver the information also in a transparent way to the users. This media can be internal to the organization or directed to the external users (citizens, businesses, etc.) [15] and [8] discuss the use of social media in software development.

If the organization aims at reaching Better Democratic Quality, we recommend the use of surveys, dedicated softwares or innovation ecosystems. [26] provides an example of survey evaluation by users through online, telephone or in person means. In terms of dedicated software, Crowd-centric Requirements Engineering (CCRE) platforms can be used to elicit, negotiate and prioritize requirements of the users and could be applied to egovernment service development [31].Regarding innovation ecosystems, a lot of successful use cases can be found in literature [13] [11]. Due to the larger scale of these methods, we formulate the hypothesis that they would be more appropriate to ensure a representativeness in the democratic participation of users. We must however note that some threats to inclusion would still be present (such as possible bias for the digital literacy).

\section{Limitations and Further Research}

As indicated at the beginning of this paper, as well as in the title, this work is an experimental study combining both qualitative and quantitative methods to understand the effect that public values have on the use of participation methods. The key limitation to this study is of course the limited number of respondents. Indeed, four cases have been selected and for each case one interview has been conducted. Although we agree that a higher number of interviews would have been welcome, we wish to underline that each of those projects was conducted by a very small number of people. As we especially wanted to interview project participants who had been involved since the start of the project and had been in the project 'cockpit', it was necessary to make some concessions on the number of interviews and potential respondents.

We suggest that further research on this topic focuses on three aspects. First of all, it would be highly relevant to conduct a number of follow-up interviews. Not only with key figures from the projects, but also with people that were involved in the project as partner or end-user only. Secondly, what we also suggest is to further validate the logic of this study as well as the findings via extra projects in which user participation methods have been used. Finally, whereas this research focused on the impact of public values on the choice for certain types of user participation methods, it would be highly interesting to gain a deeper understanding on the effect of public values on the fact that user participation methods are used at all. In order to understand this relationship, it would be necessary to also analyses cases in which no user participation methods were used.

\section{Conclusion}

By exploring the influence of public values on the choice of user participation methods in an e-government context, this paper contributes at several levels. First, it analyzes the balance in public values in four e-government projects and thus further empirically validates the taxonomy of [18]. 
Second, thanks to in-depth interviews, we provide understanding about the drivers behind the use of participation methods. Third, we formulate hypotheses about the appropriate method to use depending on the context and the public values driving the organization. Finally, we also created several new leads for further research by opening a research space on the relation between public values and user participation, on the crossroads between public administration research and information systems research.

\section{Appendices}

\section{Semi-Structured Interview Guide (Qualitative)}

\section{Public Values}

Open questions

When were you first involved with project $\mathrm{X}$ ?

How did you get involved for the first time?

What motivated you to participate in the project?

What does the project/organization mean to you?

Which goals are the most important to achieve in the project?

Expectations

What were your expectations about the project?

What did you expect from the other participants of the project?

What did you think the result would be?

Is the reality now different from what you initially expected?

Values

What do you think are the most important characteristics that you need to have in order to contribute to the project?

Do you think it is important to think about the general interest, or rather about your own interest?

\section{User Participation}

Does your organization include the users in the creation of its eservices?

Why does your organization include users in the creation of eservices? [Open Question]

At which stage does your organization include the users in the creation of e-services? [Open Question]

How does your organization collect the requirements of users?

[Open Question] $\rightarrow$ [Present List of 8 Methods]

How often does your organization use one of those methods?

Why did you choose this particular method?

Which situations do you find difficult in the project?

Can you give me an example in which it is difficult to make a decision?

How did you deal with this situation?

\section{Ranking Game (Quantitative)}

What are/were the most important values for you in the context of your project? [Present randomly the different public values and ask to rank from most important to least important]

\section{References}

[1] Andersen, K.V. and Henriksen, H.Z. 2006. E-government maturity models: Extension of the Layne and Lee model. Government Information Quarterly. 23, 2 (2006), 236248. DOI:https://doi.org/10.1016/j.giq.2005.11.008.

[2] Axelsson, K. et al. 2010. Exploring the importance of citizen participation and involvement in e-government projects. Transforming Government: People, Process and $\begin{array}{llll}\text { Policy. } & 4, & 4 & \text { (2010), 299-321. }\end{array}$ DOI:https://doi.org/10.1108/17506161011081309.

[3] Ayed, H. et al. 2017. Agile cultural challenges in Europe and Asia: Insights from practitioners. Proceedings - 2017 IEEE/ACM 39th International Conference on Software Engineering: Software Engineering in Practice Track, ICSE-SEIP 2017 (2017), 153-162.

Baarda, B. (Dirk B. et al. 1996. Basisboek open interviewen: praktische handleiding voor het voorbereiden en afnemen van open interviews. Stenfert Kroese.

[5] Berntzen, L. and Johannessen, M.R. 2016. The Role of Citizen Participation in Municipal Smart City Projects: Lessons Learned from Norway. Smarter as the New Urban Agenda. Springer International Publishing. 299314.

[6] Billestrup, J. and Stage, J. 2014. E-government and the Digital Agenda for Europe A Study of the User Involvement in the Digitalisation of Citizen Services in Denmark. (2014), 71-80.

[7] Bøgh Andersen, L. et al. 2013. Public Values and Public Service Motivation: Conceptual and Empirical Relationships. American Review of Public Administration. 43, 3 (2013), 292-311. DOI:https://doi.org/10.1177/0275074012440031.

[8] Bonsón, E. et al. 2012. Local e-government 2.0: Social media and corporate transparency in municipalities. Government Information Quarterly. 29, 2 (2012), 123 132. DOI:https://doi.org/10.1016/j.giq.2011.10.001.

[9] Boyce, C. and Neale, P. 2006. Conducting in-depth interviews: A Guide for designing and conducting indepth interviews. Evaluation. 2, May (2006), 1-16. DOI:https://doi.org/10.1080/14616730210154225.

[10] Bozeman, B. 2009. Public values theory: three big questions. International Journal of Public Policy. 4, 5 (2009), 369-375.

[11] Briscoe, G. and Mulligan, C. 2014. Digital Innovation: The Hackathon Phenomenon.

[12] Chan, C.M.L. and Pan, S.L. 2008. User engagement in egovernment systems implementation: A comparative case study of two Singaporean e-government initiatives. Journal of Strategic Information Systems. 17, 2 (2008), 124-139. DOI:https://doi.org/10.1016/j.jsis.2007.12.003.

[13] Cossetta, A. and Palumbo, M. 2014. The Co-production of Social Innovation: the case of Living Lab. Smart City: How to Create Public and Economic Value with High Technology. 221-233.

[14] Van Dyke, V. 1962. Values and Interests. The American Political Science Review. 56, 3 (1962), 567-576. 
[15] Feeney, M. and Welch, E. 2016. Technology-Task Coupling: Exploring Social Media Use and Managerial Perceptions of E-Government. American Review of Public Administration. $\quad 46, \quad 2$ (2016), 162-179. DOI:https://doi.org/10.1177/0275074014547413.

[16] Hartwick, J. and Barki, H. 1994. Explaining the role of user participation in information system use. Management Science. $\quad 40, \quad 4$ (1994), 440-465. DOI:https://doi.org/10.1287/mnsc.40.4.440.

[17] Heeks, R. 1999. The Tyranny of Participation in Information Systems: Learning from Development Projects.

[18] Jaspers, S. and Steen, T. 2018. Realizing public values: enhancement or obstruction? Exploring value tensions and coping strategies in the co-production of social care. Public Management Review.

[19] Johnson, R.B. et al. 2007. Toward a Definition of Mixed Methods Research. Journal of Mixed Methods Research. 1, 2 (2007), 112-133. DOI:https://doi.org/10.1177/1558689806298224.

[20] Karkin, N. and Janssen, M. 2014. Evaluating websites from a public value perspective: A review of Turkish local government websites. International Journal of Information Management. 34, 3 (2014), 351-368. DOI:https://doi.org/10.1016/j.ijinfomgt.2013.11.004

[21] Kernaghan, K. 2003. Integrating values into public service: The values statement as centerpiece. Public Administration Review. 63, 6 (2003), 711-719.

[22] Kluckhohn, C. 1952. Values and value-orientations in the theory of action: An exploration in definition and classification. Towards a general theory of action. $\mathrm{T}$. Parsons and E.A. Shills, eds. Harvard University Press. 388-433.

[23] Mahaux, M. and Maiden, N. 2008. Theater improvisers know the requirements game. IEEE Software. 25, 5 (2008),

$68-69$. DOI:https://doi.org/10.1109/MS.2008.128.

[24] Minichiello, V. et al. 2008. In-depth interviewing: Principles, techniques, analysis.

[25] Oostveen, A.-M. and Van Den Besselaar, P. 2004. From small scale to large scale user participation: A case study of participatory design in e-government systems. Proceedings of the eighth conference on Participatory design Artful integration interweaving media materials and practices PDC 04. (2004), 173-182.
DOI:https://doi.org/10.1145/1011870.1011891.

[26] de Róiste, M. 2013. Bringing in the users: The role for usability evaluation in eGovernment. Government Information Quarterly. 30, 4 (2013), 441-449. DOI:https://doi.org/10.1016/j.giq.2013.05.007.

[27] Simonofski, A. et al. 2019. Co-Creating e-Government Services: An Empirical Analysis of Participation Methods in Belgium. Setting Foundations for the Creation of Public Value in Smart Cities. Springer.

[28] Simonofski, A. et al. 2018. From Traditional to Agile EGovernment Service Development: Starting from Practitioners' Challenges. 24th Americas Conference on Information Systems (New Orleans, 2018).

[29] Simonofski, A. et al. 2017. Reexamining E-participation : Systematic Literature Review on Citizen Participation in E-government Service Delivery. Twenty-third Americas Conference on Information Systems (Boston, MA, 2017).

[30] Simonofski, A. et al. 2018. The Impact of User Participation Methods on E-Government Projects: The Case of La Louvière , Belgium. Media and Communication. 6, November (2018), 175-186. DOI:https://doi.org/10.17645/mac.v6i4.1657.

[31] Snijders, R. et al. 2015. Crowd-Centric Requirements Engineering: A method based on crowdsourcing and gamification. Department of Information and Computing Sciences, Utrecht University, Tech. Rep. UU-CS-2015004. March (2015)

[32] Stebbins, R. 2001. What Is Exploration? Exploratory Research in the Social Sciences.

[33] Storey, M. et al. 2010. The impact of social media on software engineering practices and tools. FSE/SDP workshop on Future of software engineering research (2010), 359-364.

[34] van Velsen, L. et al. 2009. Requirements engineering for e-Government services: A citizen-centric approach and case study. Government Information Quarterly. 26, 3 (2009), $477-486$. DOI:https://doi.org/10.1016/j.giq.2009.02.007.

[35] Wijnhoven, F. et al. 2015. Open government objectives and participation motivations. Government Information Quarterly. 32, 1 (Apr. 2015), 30-42. DOI:https://doi.org/10.1016/j.giq.2014.10.002. 